Dermatology 2008;216:364-365

DOI: 10.1159/000117709

\section{Genital HPV Lesions and Molluscum Contagiosum Occurring in Patients Receiving Anti-TNF- $\alpha$ Therapy}

Christina Antoniou, Maria G. Kosmadaki, Alexandros J. Stratigos, Andreas D. Katsambas

Department of Dermatology, A. Sygros Hospital, University of Athens, Athens, Greece

\section{Key Words}

Etanercept $\cdot$ Human papillomavirus, genital $•$

Immunosuppression - Infliximab $\cdot$ Molluscum contagiosum •

Psoriasis $\cdot$ Tumor necrosis factor

Biological agents that act as immune response modifiers have emerged as novel therapeutic options for the control of moderate to severe psoriasis [1]. Treatment with TNF- $\alpha$ antagonists has been associated with infections from various pathogens including viral, bacterial, fungal and protozoan organisms $[2,3]$. We report 1 case of genital human papillomavirus (HPV) recurrence after treatment with etanercept and 1 case of HPV exacerbation and molluscum contagiosum appearance after infliximab infusion.

\section{First Case}

In December 2006, a 31-year-old woman with psoriasis and psoriatic arthritis was started on etanercept $50 \mathrm{mg}$ s.c. twice per week. Laboratory assessment (including HIV test) was normal. Three days after the first dose her arthritis was greatly improved. On week 12 , the PASI score improved by more than $75 \%$ and the dose was reduced to $25 \mathrm{mg}$ twice per week. On week 24, psoriasis was further improved. The patient complained about condylomata of the perianal area which had been present at least 2 months before her last presentation to the clinic. Etanercept was discontinued, and HPV was successfully treated with 2 sessions of cryotherapy. Proctoscopy and PAP smear were normal. The patient had a history of condylomata acuminata approximately 10 years ago, which had been treated with podophyllo-

C.A. and M.G.K. contributed equally to the work. toxin until resolution without further appearance (PAP smear was also normal at that time). She had had a constant partner for the past 3 years who had no clinical HPV infection or history of condylomata. The patient had received ciclosporin 2.5 years ago and 5 courses of narrow-band UVB, the last of which ended in June 2004. No HPV recurrence or condyloma was noted at that time.

\section{Second Case}

A 29-year-old patient with chronic plaque psoriasis (PASI score of 20.4 at baseline) was treated with efalizumab with an excellent clinical response. Twenty-one months after initiation of efalizumab treatment, a generalized inflammatory flare (PASI score 30.5) was observed, in the absence of infection. Ciclosporin $3.5 \mathrm{mg} / \mathrm{kg}$ daily was then given for 1 month in combination with efalizumab, but psoriasis continued to worsen (PASI 34.6). Efalizumab and ciclosporin were discontinued, and infliximab (5 mg/ $\mathrm{kg}$ ) was introduced, 1 week after the discontinuation of the previous 2 drugs. Laboratory assessment was normal. Two weeks after the first infusion, the patient presented with a significant improvement (PASI 16.5). The blood leukocyte count was 9,300/ $\mathrm{mm}^{3}$ consisting of $36 \%$ neutrophils and $53 \%$ lymphocytes, and the patient was HIV negative. However, molluscum contagiosum was observed in the lower abdomen, at sites not recently involved by psoriasis, and preexisting HPV lesions of the genital area (which were not noted on initial examination) were exacerbated. Both viral infections were very pronounced in terms of size and number of lesions. Infliximab was discontinued. The condylomata were treated with 3 sessions of cryotherapy followed by imiquimod cream application, whereas the mollusca were treated by manual expression of the central core. PAP smear was normal. Methotrexate (15 mg/week) was started 1 month after infliximab withdrawal.

\section{Discussion}

TNF- $\alpha$ plays an important role in the immune response to infection. When it is inhibited, the production of cytokines and chemokines, the expression of cell surface MHC class I and II as well as the proliferation and apoptosis of $\mathrm{T}$ lymphocytes may be affected. Thus, the recognition of microorganisms by phagocytes and dendritic cells as well as the activation of T lymphocytes may be impaired. Furthermore, TNF- $\alpha$ is involved in signaling apoptosis in infected cells, a mechanism employed in an effort to stop viral replication and spread. E6 protein of HPV-16 is known to directly bind to TNF receptor 1 and abrogate TNF-induced apoptosis of the host cell [4]. Similarly, molluscum contagiosum viral proteins were also reported to interfere with the apoptotic pathway of the host cell signaled by TNF receptor 1 [5].

\section{KARGER}

() 2008 S. Karger AG, Basel

Fax +41613061234

E-Mail karger@karger.ch

www.karger.com 
Given the temporal relation between the beginning of etanercept treatment and the onset of HPV recurrence in our first patient and the fact that the patient had not received any other immunosuppressive therapy in the recent past, we speculate that HPV recurrence could be associated with etanercept therapy. To our knowledge, this is the first report of HPV reactivation while under treatment with etanercept. The occurrence of multiple molluscum contagiosum lesions despite normal lymphocyte counts and the exacerbation of HPV infection in our second patient may be explained by the compromised direct interaction of viral proteins with TNF receptor 1 , as well as by depletion of TNF$\alpha$ caused by infliximab. Molluscum contagiosum appearance has also been reported after 6 months of infliximab and methotrexate therapy [6].

The effect of anti-TNF- $\alpha$ treatment on HPV and molluscum contagiosum infections needs to be evaluated by further clinical observations and other studies. However, given the involvement of TNF- $\alpha$ in T-cell-mediated immunity, physicians should be alert to a possible higher susceptibility of anti-TNF- $\alpha$-treated patients to viral infections of the skin.

\section{References}

1 Heenen M, Simonart T: Biological agents and psoriatic epidermis: what are we ultimately targeting? Dermatology 2006;212:321-323.

2 Winthrop KL: Risk and prevention of tuberculosis and other serious opportunistic infections associated with the inhibition of tumor necrosis factor. Nat Clin Pract Rheumatol 2006;2:602-610.

3 Nathan DM, Angus PW, Gibson PR: Hepatitis B and C virus infections and anti-tumor necrosis factor-alpha therapy: guidelines for clinical approach. J Gastroenterol Hepatol 2006;21:1366-1371.

4 Filippova M, Song H, Connolly JL, Dermody TS, Duerksen-Hughes PJ: The human papillomavirus $16 \mathrm{E} 6$ protein binds to tumor necrosis factor (TNF) R1 and protects cells from TNF-induced apoptosis. J Biol Chem 2002;277:21730-21739.

5 Hu S, Vincenz C, Buller M, Dixit VM: A novel family of viral death effector domain-containing molecules that inhibit both CD-95- and tumor necrosis factor receptor-1-induced apoptosis. J Biol Chem 1997; 272:9621-9624.

6 Cursiefen C, Grunke M, Dechant C, Antoni C, Junemann A, Holbach LM: Multiple bilateral eyelid molluscum contagiosum lesions associated with TNFalpha-antibody and methotrexate therapy. Am J Ophthalmol 2002;134:270-271.

Dr. Maria Kosmadaki

University of Athens, A. Sygros Hospital

Department of Dermatology, 5 Ionos Dragoumi Street

GR-16121 Athens (Greece)

Tel. +306936910123, Fax +30 2103318573

E-Mail kosmadaki@gmail.com 